\title{
Rock mass response to deep mining induced stress- research and tools development at the CEMI, Canada
}

\author{
D.J. Duff Centre for Excellence in Mining Innovation (CEMI), Canada \\ B. Valley Centre for Excellence in Mining Innovation (CEMI), Canada \\ B. Milkereit Department of Physics, University of Toronto, Canada
}

J. McGaughey Mira Geoscience, Canada

\begin{abstract}
Mining deeper is needed in order to sustain production in many established camps worldwide, but this comes with elevated risk due to, among other things, high stresses. In these conditions, the interactions between stress and structure become critical, as does the state of the rock mass itself and how it's impacted by the process of mining. Research leading to optimised mine designs and an improved geomechanics outcome is needed. Specifically, rock mass system stiffness and its effect on the stability of structures, the performance of our ground support, and thereby the vulnerability of our excavations is critical to consider, but is not easily measured or understood. This is despite its fundamental importance. At a strategic level, work needs to focus on an integrated approach comprised of enhanced early site characterisation techniques/procedures coupled with rock mass behaviour monitoring in response to the mining process itself. Recognition of the inherently dynamic, rather than static, conditions which prevail in deep mines is essential to ensuring that strategic goals are met through employment of appropriate tactics. This paper will discuss the difficulties and hazards associated with unpredictable rock mass behaviour in deep mines and examine in some detail various tactical research and tool development approaches being undertaken to lower the risk associated with them.
\end{abstract}

\section{Introduction}

Strategies to manage stress and stress distribution and the impact they can have on the stability of geological structures in underground deep mines are needed to ensure the orderly and safe extraction of ore. Once a mining method has been chosen, current practices largely rely upon numerical and empirical modelling methods for determining optimal stope sequencing and related ground support needs.

However, this, when coupled with an inconsistent rock mass characterisation approach before mining, and little or no monitoring of the performance of that same rock mass to the process of mining itself, is not an optimal strategy to recover maximum value from an orebody.

Specifically, there is too little attention paid to the notion of system stiffness. Whereas our focus tends to be on the critical parameters which influence fault behaviour, i.e. fault geometry, fault characteristics and fault stiffness (both normal and shear); the overall system stiffness and how it is being altered and impacted by the mining process itself is poorly understood and receives too little attention. This is despite the fact that it largely determines the violence with which energy is released by seismic events in mines.

A dual approach is required which supplies practitioners not only with the tools and guidelines they need today for application in such situations but also the new knowledge and ideas capable of further enhancing our opportunities for optimal orebody value recovery in the future (Figure 1). 


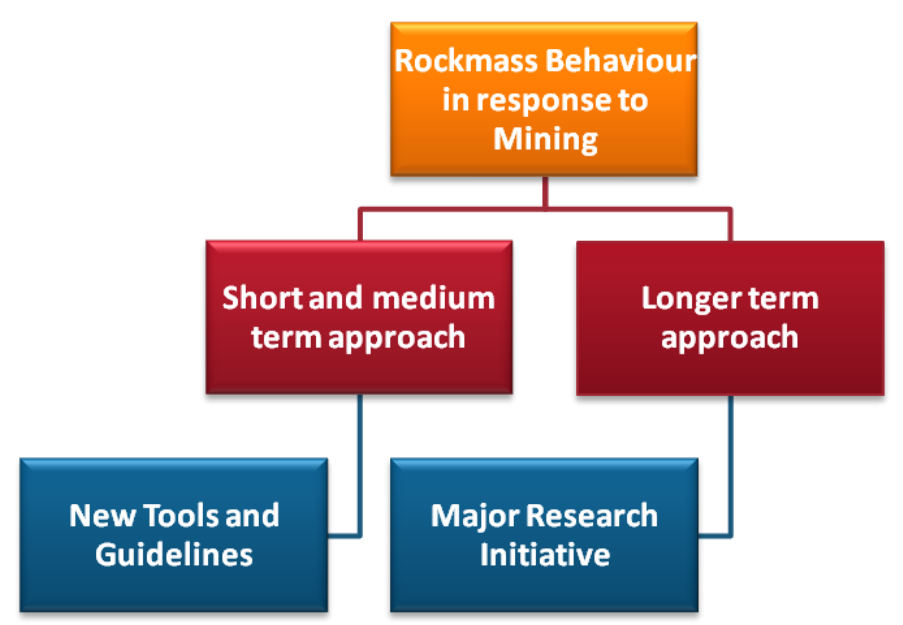

Figure 1 Dealing with rock mass behaviour response to mining strategically

This is particularly important in our deep mines where multiple non-geotechnical challenges are also posed and the selection of an appropriate strategy, when coupled with complimentary tactics, will help to mitigate risk and increase investor confidence both outside mining companies and within them, thereby leading more easily to project approval.

\section{The importance of a complex stress field and history}

Rock masses retain a stress signature which reflects their evolution and tectonic history (Figure 2). These in situ stresses, once exposed to the effects of mining are altered, are redistributed and sometimes completely rotated. The effect is to introduce system disequilibrium and to potentially render erstwhile stable structures suddenly unstable and, in some cases, to even cause new structures to form.



In situ condition inherited from tectonic history



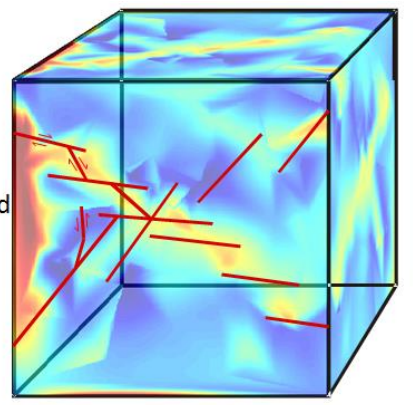

Slip on existing fault and new ruptures accommodate system changes

Figure 2 The effect of mining on in situ stress conditions (Valley and Duff, 2011; Milkereit et al. , 2010)

The results for deep mines are manifested in increased risks, particularly those posed by the threat of rockbursting which, when of the fault slip caused kind, can result in both significant risk to workers as well as in substantial capital asset exposure and potentially production disruption.

\section{An integrated approach to dealing with risks associated with mining induced stress issues}

At its most fundamental, dealing with mining induced stresses is about understanding the impact of our mine design and plan on the rock mass itself. Our current suite of available tools and guidelines for everyday use by practitioners is somewhat inadequate and more suited to dealing with assumed static conditions. However, they are not well suited to dealing with the reality of constantly changing dynamic 
conditions typical of most underground deep mines. Furthermore, they do not help to tackle the longerterm more strategic issue of mitigating the risks associated with rockbursting caused by fault slip.

To address both of these issues, CEMI, through its GeoRisk Strategic Research Program, has developed a strategy aimed at addressing relevant issues in the short- to medium-term and longer-term.

In the short- and medium-term, CEMI has supported, and is supporting, the development of several different tools and guidelines on behalf of industry which, in the hands of a qualified practitioner, will lead to significant performance improvement in mines. As part of this effort, new knowledge creation is being sponsored through the support of nine post-graduate students at four universities.

Further, the longer-term problem of fault slip caused rockbursting is the subject of a multi-year, multi-discipline and institution major research initiative, led by CEMI, which formally commenced in the third quarter of 2011. An overview of both is provided in the ensuing sections of this paper.

\section{1 Tools and guidelines}

The following are either already available for use by industry or are under development:

\section{1. 1 GeoHazMap}

Based upon a model developed for exploration geologists to assist in mineral prospectivity mapping, CEMI, through Mira Geoscience in Montréal, has helped to sponsor development of a GoCAD-based software tool capable of assessing the whereabouts in underground mines of those places most at risk for fault slip caused rockbursting.

Using a 4D weights of evidence approach, the tool virtually paints excavation walls according to the rockburst hazard posed (Figure 3). It differs from other tools which aspire to a similar outcome by relying on all available geotechnical information not just microseismicity.



Figure 3 GeoHazMap tool (McGaughey, 2011) 
During development of the tool and its 'training' through exposure to over 150 fault slip caused rockburst events at two mines in Sudbury, Ontario, the optimal weighting of various geotechnical parameters leading to hazard recognition was determined. Development results indicated that $75 \%$ of the actual rockbursts were among the top $25 \%$ of hazards recognised by GeoHazMap in the ore zones, whereas $90 \%$ were among the top $25 \%$ of hazards recognised in the footwall rocks. The tool is now commercially available.

\section{1.2 Phase 28.0}

Uncertainties and variability are the rule when dealing with the natural environment. Our current deterministic approach, which assumes a given input or set of input parameters, will always produce the same output or lead to a single answer, is overly simplistic. Reliable mine design must deal with the statistical variation of input parameters and design criteria (Valley and Duff, 2011).

Working with Rocscience in Toronto, Canada, CEMI has facilitated the addition of statistical variation capability using the Rosenbleuth PEM method to the Phase $^{2}$ software package thereby permitting erstwhile unavailable probability analysis (Figure 4).

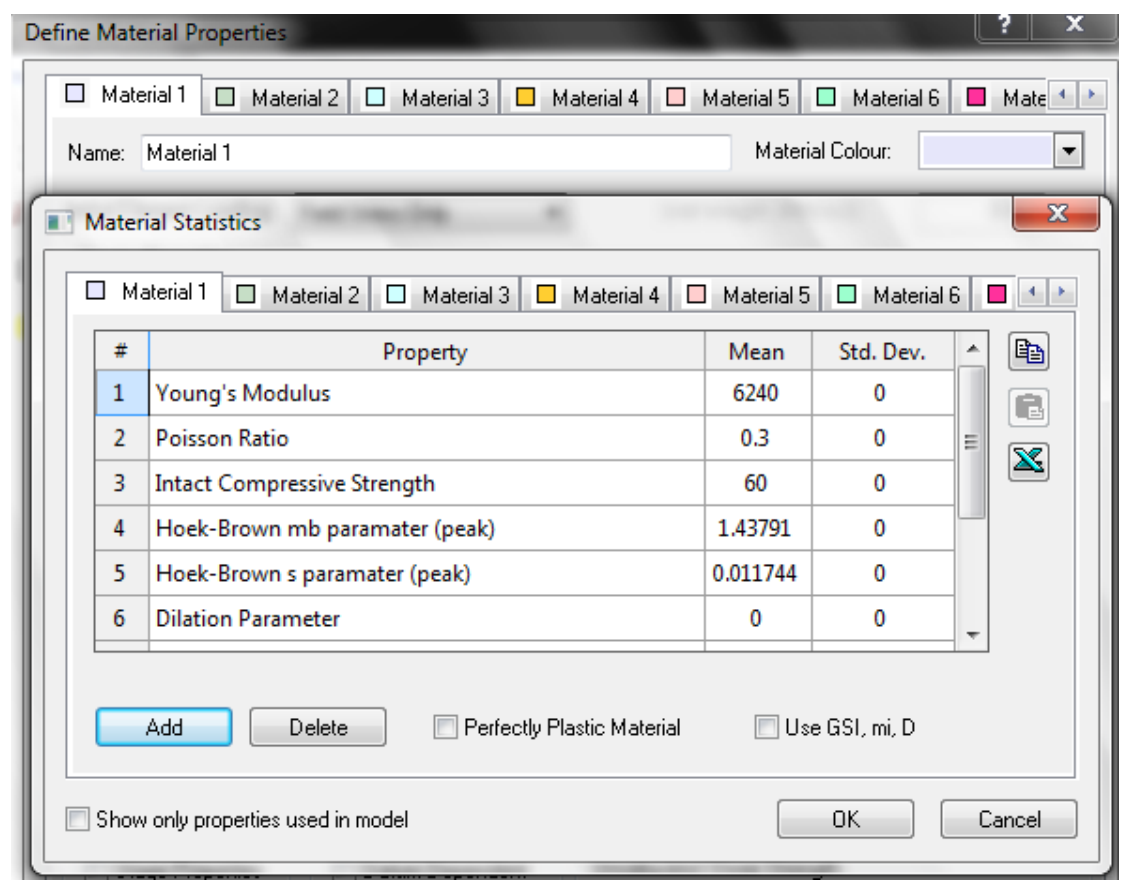

Figure 4 Statistical treatment of data input parameters

Query lines now run adjacent to excavation openings; for example, will now return a range of possible outcomes with error bars rather than a single mean value, as before. Note: as with all tools of this kind, sound experienced judgement should always be exercised.

\subsubsection{Structural geology guidelines for aiding the characterisation of deep mining fault behaviour}

Working with Golder Associates Canada and Queen's University (Ontario, Canada), CEMI has made available (released in Quarter 2, 2011) a guidelines handbook designed to help mine geologists and rock engineers develop a workflow to better understand, evaluate and interpret rock mass conditions that might create problematic fault slip-type seismicity or rockbursting in underground mines (Figure 5). 


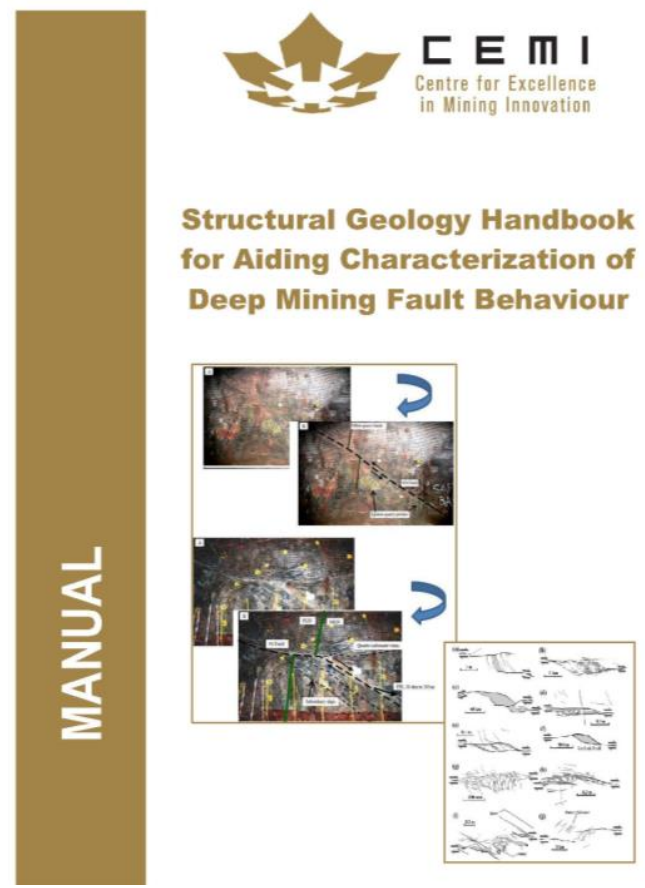

Figure 5 Structural Geology Guidelines (Carter and Bewick, 2011)

Too little attention is paid by mine geologists and rock mechanics engineers alike to fabric and structures which, during the life of a mine, can vary from stable to unstable, thereby impacting upon excavation vulnerability and worker safety. This handbook is about re-acquainting professionals with the importance of structural characterisation in order to enable maximum design flexibility to handle possible failures. 'Fookes-like' (Fookes et al., 2000) block diagrams or cartoons are included for most major ore deposit types to better assist mine design engineers with overall structure conceptualisation and are linked to known risks associated with such deposits from worldwide experience.

\section{1. 4 BurstSupport tool}

Currently, we largely rely on rules of thumb and empirical evidence to guide our selection of ground support in our deep mines. This is supplemented by the teachings captured in the 1996 Canadian Rockburst Research Program (CRRP, Kaiser, 1996). However, due to the fundamentally dynamic nature of conditions in those deep mines there is a need for a tool which would enable optimum strategies to be developed to deal with burst proneness, i.e. dynamic rather than just static conditions.

CEMI is supporting the development of guidelines and software tools at Laurentian University in Sudbury, Canada which, when completed, will enable rock mechanics engineers to more effectively perform their jobs.

A set of guidelines will be produced which represent the updated relevant sections of the CRRP, and a new Windows-based software tool is developed (Figure 6). This software tool will be capable of allowing a variety of input parameters to be selected, including current dynamic support components, to better deal with anticipated ground conditions under dynamic loading conditions. The guidelines will be available in Quarter 1, 2012 and the software tool in Quarter 1, 2013. 




Figure 6 BurstSupport tool (Cai and Duff, 2010)

\subsubsection{S-GMAT - synthetic ground motion monitoring tool}

The effect that a seismic 'bump' will have on an adjacent excavation depends upon the size or magnitude of the event and its distance from the excavation (Kaiser, 1996). Since the ground motions associated with an event are much larger at the source than at a distance from it, the relationship between the two is described by a scaling law. However, the assumed scaling law is considered no longer sufficient because much more sophisticated monitoring systems are now standard in mines.

CEMI has contracted the International Mine Seismology (IMS) group to develop a stand alone or web-based S-GMAT that can be used to identify in 3D what ground motions are to be expected at various distances from a fault rupture point. A better understanding of these, when combined with the functionality of the BurstSupport Tool, will help practitioners make better ground support decisions.

A basic 2D simulation is depicted in Figure 7. Slightly more detailed geology and structure will eventually be incorporated and anticipated final outputs will include ground motion contours which can be exported to generate charts of ground motion versus distance from source. The tool should be available in early 2012.
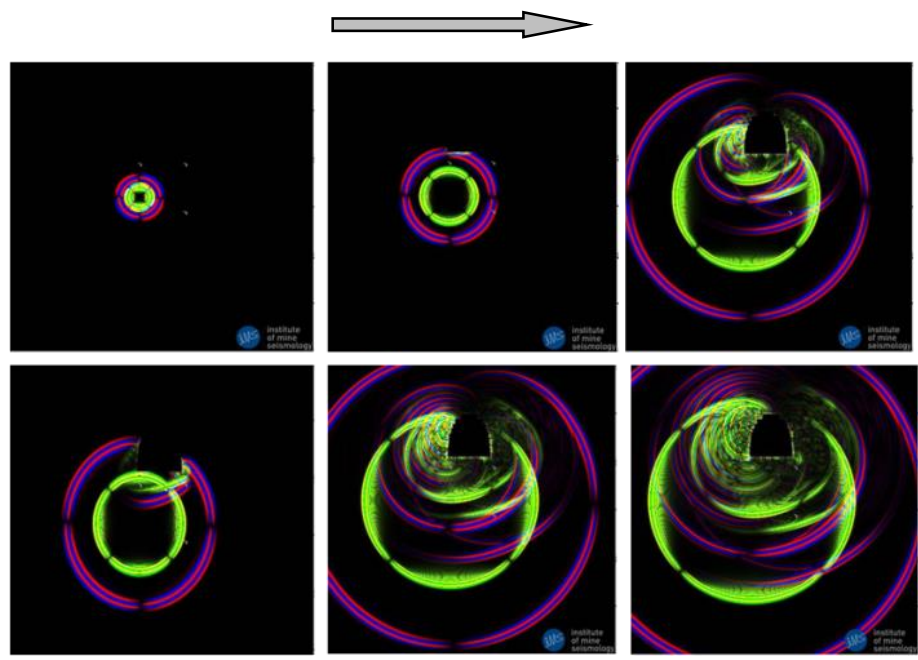

Figure 7 2D simulated fault rupture near excavation opening showing radiating $P$ and $S$ waves (image courtesy of IMS Group)

\section{1.6 GeoRisk manual}

It is suggested that guidelines which adequately deal with geotechnical hazard and risk are needed to assist with mine design; and that too little appreciation of the importance of geotechnical hazards and the risk they pose to health and safety and to mining infrastructure may exist at present. The numerous uncertainties associated with geological understanding, the exposure of people to potential hazards in the 
workplace and the need to provide a specific dollar outcome requires a proper assessment of risk (Steffen, 2007).

CEMI is sponsoring the development of a GeoRisk Manual involving researchers from Mining Innovation Rehabilitation and Applied Research Corporation (MIRARCO) in Sudbury and Queen's University in Kingston, Canada, to assist in dealing with geotechnical uncertainties associated with mine design; with a specific focus at the pre-feasibility and feasibility study stages where one's ability to influence change can result in the maximum impact.

Of particular importance to demonstrate is that some emphasis is being placed upon the specific components of a proper geotechnical mine design model, namely that it is comprised of hazards that may originate with the design model (whether empirical or numerical); the mining method model; the geotechnical model (comprised of rock mass and other characterisation data) and the behaviour/failure model.

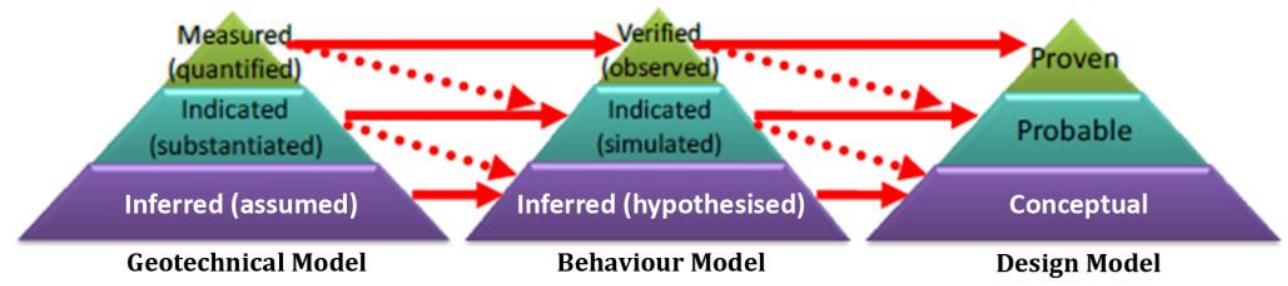

Figure 8 Arrows indicating the possible confidence level evolution paths when considering geotechnical risk for a mining project (Kaiser et al., 2011)

Using a confidence-based approach similar to that used for mineral resource estimates (such as JORC, CIM or SAMREC), it is postulated that for each of the hazards mentioned, the confidence level in our assessment of them grows over time from basic or conceptual to more advanced or proven (Figure 8).

The benefit of this approach lies in its ability to facilitate communication of our state of awareness of project geotechnical risk while at the same time drawing attention to where knowledge or data gaps needing to be filled may exist. It is expected that the GeoRisk Manual will be ready for release before the end of 2011.

\subsubsection{Strain monitoring as a means to understand rock mass behaviour and system stiffness}

Whilst some time and effort is now spent at project pre-feasibility and feasibility study stages to describe rock mass geology, including the prominent structural features within it, insufficient attention is paid to describing its anticipated behaviour (Kaiser et al., 2011). This can lead to numerical models which are likely wrong, designs which are either uneconomic or unsafe and constructability issues which can be very costly.

During mining, rock mass behaviour monitoring is not routinely performed and improvements are needed to better understand the performance of our designs in response to prevailing conditions. Neither is the issue of system stiffness well understood, nor easily addressed, yet impacts on the stability of structures and energy release rates can be profound (Figure 9). 


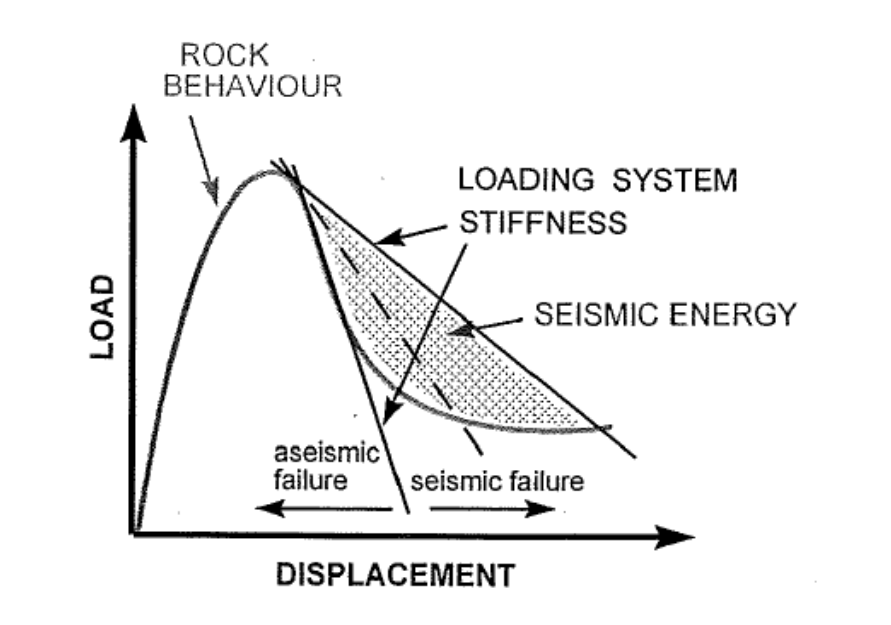

Figure 9 Release of seismic energy (Kaiser et al., 1995; Kaiser, 1996). NB. system stiffness is a property of a structural system which depends upon the deformability of the materials that form the system, as well as the system's geometry (Bewick, 2011)

Strain/deformation measurements are one way to gauge the response of the rock mass to the mining process, but they suffer from being too few in number at most mines to provide any meaningful data.

Fibre optics-based deformation monitoring can help address this issue by providing relatively inexpensive 'cloud-like' coverage of broad areas within mines. Using distributed array and other systems capable of measuring at a range of frequencies, both fast and slow strain responses in the rock mass may be tracked.

With the assistance of Vale in Sudbury, and in conjunction with researchers based at the University of Toronto, CEMI is currently engaged in a project designed to instrument a $30 \times 305 \times 153 \mathrm{~m}$ sill pillar at the Coleman Mine with an array of instrument types; including fibre optics strain measurement cables, MPBX multi-point extensometers, acoustic televiewer (ATV), optical televiewer (OTV), direct current/induced polarization (DC/IP) cross-hole tomography, accelerometers, light detection and ranging (LIDAR) and physical properties (Figure 10).

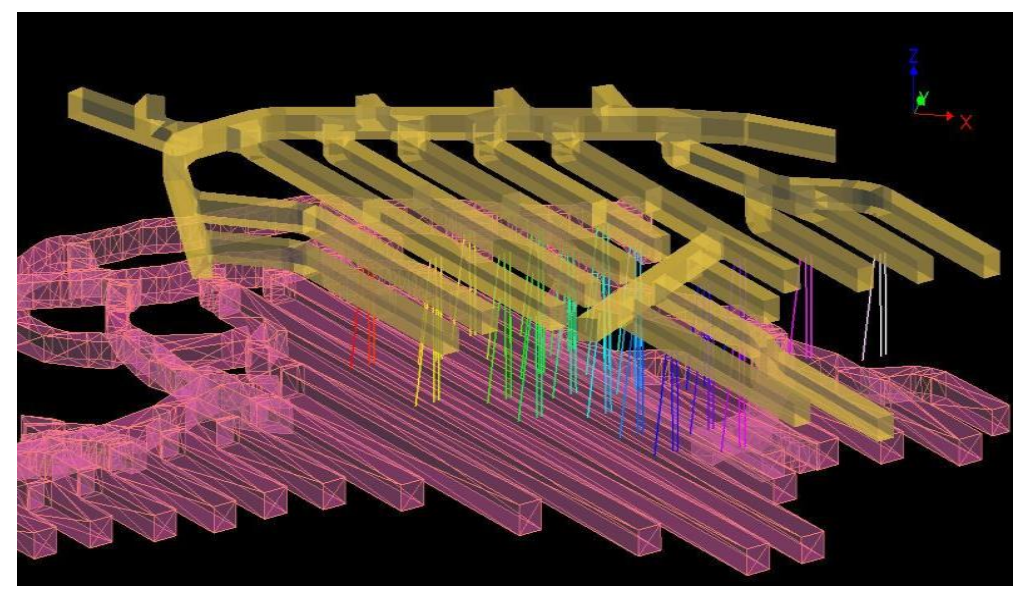

Figure 10 Instrumented boreholes in sill pillar at Coleman Mine (courtesy Vale)

The system, although experimental in nature, is designed to work with all components acting in a complementary fashion to:

- Conduct standard and enhanced rock mass characterisation - including differential change measurement.

- Monitor displacement, stress changes as well as rock mass degradation. 
- Integrate all existing and newly collected data within a 4D framework for analysis and interpretation.

Instruments are both wall and borehole mounted and will complement a 'beefed up' array of both uniaxial and triaxial seismic sensors.

Setup was being completed at time of writing and few experimental results were available for reporting at the time.

\section{2 Major fault slip focussed research initiative}

Those in industry now facing the geomechanics issues associated with deep mining have suggested that identifying pre-event controls capable of mitigating the risks associated with major fault slip caused rockbursting is of major significance to them. As mines go deeper, the frequency of such events has increased at many mines and the negative impacts, both on production and on investor confidence, are substantial.

To address this, CEMI has been consulting with industry, consultants and with academics since 2009 in an effort to identify the research gaps which need to be filled in order to come to terms with fault slip control. Six workshops involving over 100 professionals were held on topics ranging from geophysics and microseismicity to structural geology and mine engineering/modelling and feedback from them suggested that further research in the areas of rock mass characterisation, rock mass behaviour monitoring, enhancing mine development rates and understanding excavation vulnerabilities in deep underground mines is required (Figure 11).
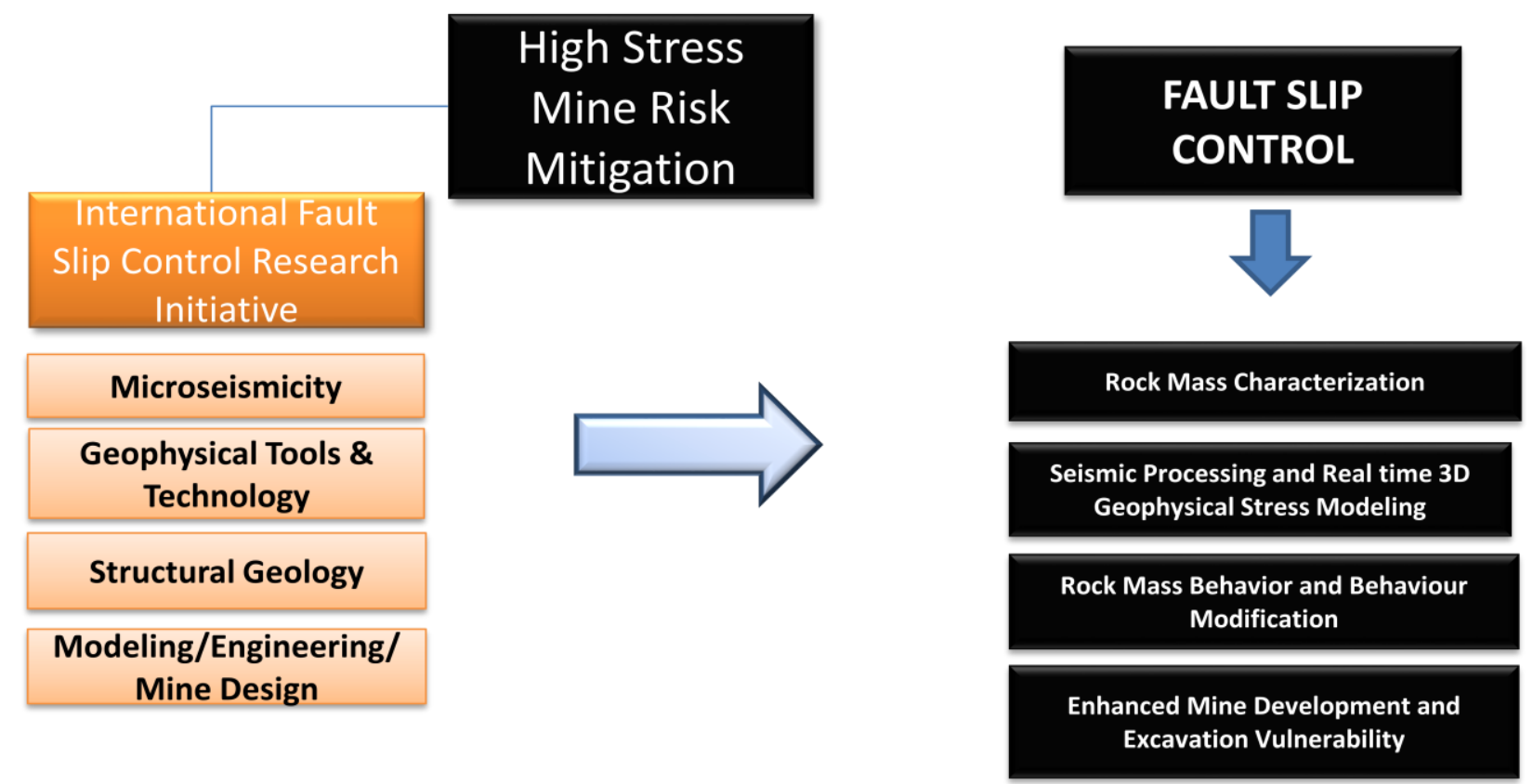

Figure 11 Workshop consultations led to the development of more focused research themes

Three primary universities in Canada have agreed to work together to enable the research needed to make this project a success: Laurentian, Queen's and University of Toronto. Equally importantly, Vale, Xstrata Nickel, Xstrata Copper and QuadraFNX have so far agreed in principle to allow researcher access to their active mine sites to conduct the necessary experiments and research aimed at helping to solve the issue of fault slip control.

With the permission of the owner companies, the Creighton, Nickel Rim South Mines and the Victoria Project in Sudbury (and potentially the Kidd Creek Mine in Timmins) will become 'living laboratories' in our 
quest for answers to important research questions aimed at understanding the conditions and mechanisms responsible for fault slip caused seismicity.

Conditions at Creighton present the ideal opportunity to understand failure mechanisms and important structure-stress field interactions, particularly in deep sill pillars (Figure 12) (O'Connor et al., 2010).



Figure 12 An advancing yield zone ahead of mining at Creighton Mine (courtesy Vale)

At Nickel Rim South, a new mine with an already sophisticated array of microseismic monitors, we can develop integrated seismic and strain monitoring networks capable of monitoring rock mass change caused by mining (Figure 13).

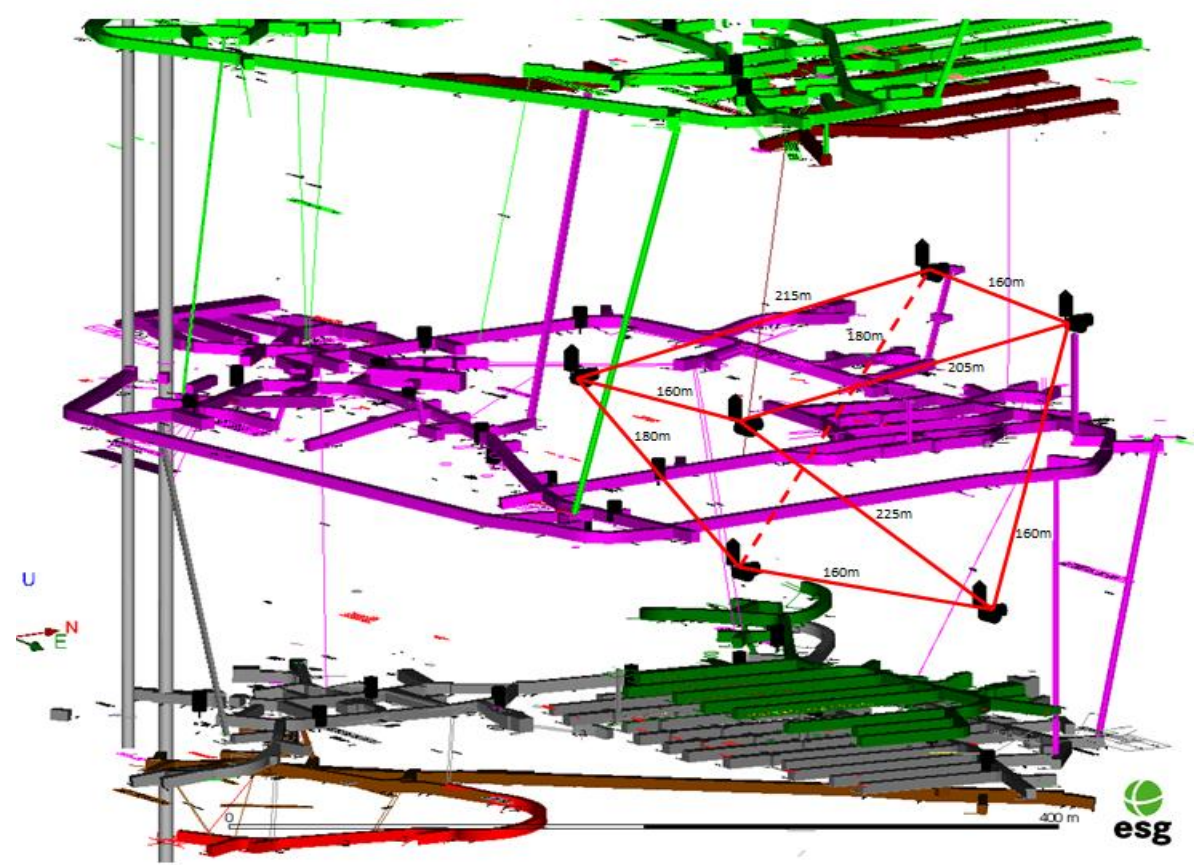

Figure $13 \mathrm{~A}$ new mine with an optimally located infrastructure for monitoring at Nickel Rim South (courtesy Xstrata Nickel) 
Lastly, at QuadraFNX's Victoria project, which currently is at the advanced exploration phase with a deep shaft being considered, an opportunity to develop sophisticated early project stage differential change rock mass characterisation criteria for deep mines is presented (Figure 14).

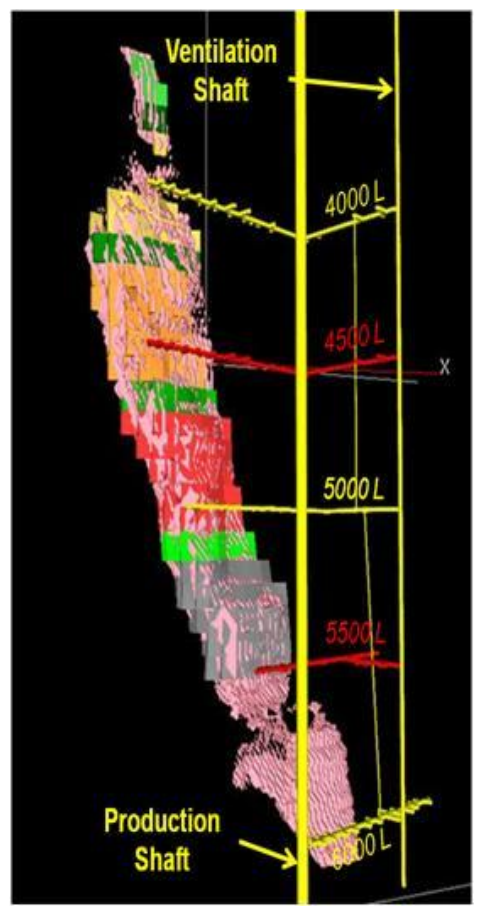

Figure 14 Differential rock mass change characterisation as the mine is being developed (courtesy QuadraFNX)

Kidd Creek Mine, if used, presents an opportunity for measurements within a large 'gravity driven' environment.

In the rock mechanics research community, this large 'living laboratory' approach is considered to be somewhat unique and, because of the active mining conditions which will prevail during measurement taking, will enable us to develop not only better pre-mining characterisation techniques and a more complete understanding of rock mass behaviour in response to mining, but also should further help in developing the next generation of sensors and analytical techniques to better understand stress-seismicity relationships in underground mines.

For example, knowing how system stiffness relationships affect instability and excavation vulnerability during mining will be addressed through the deployment of distributed integrated networks of sensors to capture rock mass behaviour. Modelling tools currently being developed will enable better planning of appropriate ground control strategies in burst-prone ground through a more accurate simulation of expected ground motion parameters near openings.

\section{$4 \quad$ Conclusions}

Research aimed at mitigating risks associated with instability and related excavation vulnerabilities in structurally complex highly stressed ground requires a strategic approach. It needs to utilise tactics aimed at not only addressing the short-term needs of the mining industry in dealing with these issues, but also the harder problems which will take more time to solve.

An integrated approach is needed, whereby tools and guidelines are produced which will have an immediate positive impact upon industries' (and researchers') ability to deal with mining induced instability issues, as is a longer-term approach to helping solve the issue of fault slip caused rockbursting and related problems in deep underground mines. 


\section{Acknow l edgements}

The contributions of the various students from multiple universities involved with this project is gratefully acknowledged as is the strong support from Vale, Xstrata Nickel, Xstrata Copper and QuadraFNX mining companies.

\section{References}

Bewick, R.P. (2011) Fault Rupture mechanics: Assessment and Understanding of Fault Behaviour using a Micro-Mechanical Approach, PhD Research Proposal, University of Toronto.

Cai, M. and Duff, D.J. (2010) Development of an Interactive Tool for Rockburst Support Design, internal CEMI proposal for new guidelines and tool development needed in support of practitioners dealing with dynamic ground support issues in underground mines.

Carter, T. and Bewick, R.P. (2011) Structural Geology Guidelines for Aiding Characterisation of Deep Mining Fault Behaviour (in preparation), Golder Associates Canada, in preparation.

Fookes, P.G., Baynes, J. and Hutchinson, J.N. (2000) Total Geological History: A model approach to the anticipation, observation and understanding of site conditions, in Proceedings of GeoEng2000: An International Conference on Geotechnical and Geological Engineering, Melbourne, Australia, Vol. 1, pp. 370-460.

Kaiser, P.K. (1996) In Canadian Rockburst Research Program 1990-1995 Handbook, A comprehensive summary of five years of rockburst research in hardrock mines, C.B. Graham (ed), CAMIRO Mining Division Vol. 1, 2, 3.

Kaiser, P.K., Tannant, D.D. and McCreath, D.R. (1995) Drift support in-prone ground, in Proceedings from the 97th CIM Annual General Meeting, CIM, pp. 277-288.

Kaiser, P.K.K., Diederichs, M.S. and Valley, B. (2011) Guidelines for GeoRisk-Based Mine Design - CEMI guidelines document (in preparation).

McGaughey, J. (2011) Forecasting Ground fall Hazard Related to Fault-Slip Rockbursting at Creighton Mine, Sudbury, Report of work to CEMI, Mira Geoscience.

Milkereit, B., Duff, D.J., Kaiser, P.K. and Schmitt, D.R. (2010) Integrated Geophysical Monitoring Systems for Deep Mines, Invited paper at 2010 AGU Conference, San Francisco.

O'Conner, C., Cotesta, L. and Brummer, R. (2010) Non-Linear Modelling Calibration Process for Vale Nickel Mines Ontario Division, in Proceedings Fifth International Seminar on Deep and High Stress Mining (Deep Mining 2010), M. Van Sint Jan and Y. Potvin (eds), 6-8 October 2010, Santiago, Chile, Australian Centre for Geomechanics, Perth, pp. 521-536.

Steffen, O. (2007) Mine planning - its relationship to risk management, in ACG Newsletter, Australian Centre for Geomechanics, Perth, December 2007.

Valley, B. and Duff, D.J. (2011) Phase2Stat - Probabilistic Analysis in Phase2Stat, in Spring 2011 Rocscience Inc. Newsletter, viewed June 2011, http://www.rocscience.com/about/newsletters. 